\title{
The Crystal Structure of Zunyite
}

\author{
By W. Barclay Kamb \\ California Institute of Technology, Pasadena, California, ${ }^{*}$ U.S.A.
}

(Received 14 February 1958)

\begin{abstract}
The structure proposed by Pauling for the rare aluminosilicate mineral zunyite $\left(\mathrm{Al}_{13}(\mathrm{OH})_{18} \mathrm{Si}_{5} \mathrm{O}_{20} \mathrm{Cl}\right)$ has been confirmed and refined with the use of $163 h k 0$ reflections and $409 h h l$ reflections obtained with Mo $K \alpha$ radiation from single crystal Weissenberg photographs. The structure is isometric $\left(T_{d}^{2}\right)$ and is built up of $\mathrm{Si}_{5} \mathrm{O}_{16}$ groups of linked silicon tetrahedra combined with $\mathrm{Al}_{12} \mathrm{O}_{16}(\mathrm{OH})_{30}$ groups of linked aluminum octahedra. Refinement is carried out independently for the $h k 0$ and $h h l$ data, and the final reliability factors are 0.12 for both sets of data. Positional parameters are refined by the least-squares method, and isotropic temperature parameters for separate atoms are adjusted with the help of difference syntheses. The refined structure differs from the trial structure by distortion of coordination polyhedra in a fashion similar to the distortions in related structures. The interatomic distance Al-O of $1 \cdot 80 \pm 0.016 \AA$ is derived for tetrahedrally coordinated aluminum. The averaged $\mathrm{Si}-\mathrm{O}$ distance is $1 \cdot 64 \pm 0 \cdot 01 \AA$. The arrangement of protons in the structure is deduced from structural arguments. The proposed arrangement requires the inclusion of at least two fluorine atoms per stoichiometric molecule, modifying the chemical formula to $(\mathrm{OH}, \mathrm{F})_{16} \mathrm{~F}_{2} \mathrm{Al}_{13} \mathrm{Si}_{5} \mathrm{O}_{20} \mathrm{Cl}$ and explaining the importance of fluorine in the formation of zunyite.
\end{abstract}

\section{Introduction}

The structure proposed by Pauling (1933) for the rare aluminosilicate mineral zunyite has several unusual features. Although the ratio $\mathrm{Si}: \mathrm{Al}$ in the substance is close to $1: 3$, the proposed structure arranges the silicon atoms together in the unique $\mathrm{Si}_{5} \mathrm{O}_{16}$ group (Fig. 1), rather than separating them in isolated $\mathrm{SiO}_{4}$ tetrahedra, as found in the polymorphs of $\mathrm{Al}_{2} \mathrm{SiO}_{5}$ and as might be expected from the zunyite formula $\mathrm{Al}_{13}(\mathrm{OH})_{18}\left(\mathrm{SiO}_{4}\right)_{5} \mathrm{Cl}$. Twelve of the thirteen aluminum atoms in the structure are octahedrally coordinated by oxygen and are linked together to form the unique group $\mathrm{Al}_{12} \mathrm{O}_{16}(\mathrm{OH})_{30}$ (Fig. 1). The thirteenth aluminum atom is in tetrahedral coordination, the $\mathrm{AlO}_{4}$ tetrahedron being isolated both from the $\mathrm{SiO}_{4}$ tetrahedra and from other $\mathrm{AlO}_{4}$ tetrahedra.

The unusual features of the structure make an examination by modern methods desirable. Pauling (1933) showed that the proposed structure was in accord with the space-group symmetry, that it accounted exactly for the dimensions of the unit cell, and that it satisfied the electrostatic valence rule (Pauling, 1939, p. 384). In addition, he calculated intensities of $72 \mathrm{X}$-ray reflections from the structure, and found good agreement with observed intensities, the value of the residual $\Sigma\left|I_{o}-I_{c}\right| / \Sigma I_{o}$ being $0 \cdot 29$. These facts were strong indication that the proposed structure was essentially correct, but no systematic verification and refinement of such a complex structure was possible at the time.

The present study was undertaken to verify the zunyite structure and to obtain accurate interatomic

* Division of the Geological Sciences, Contribution No. 956 .
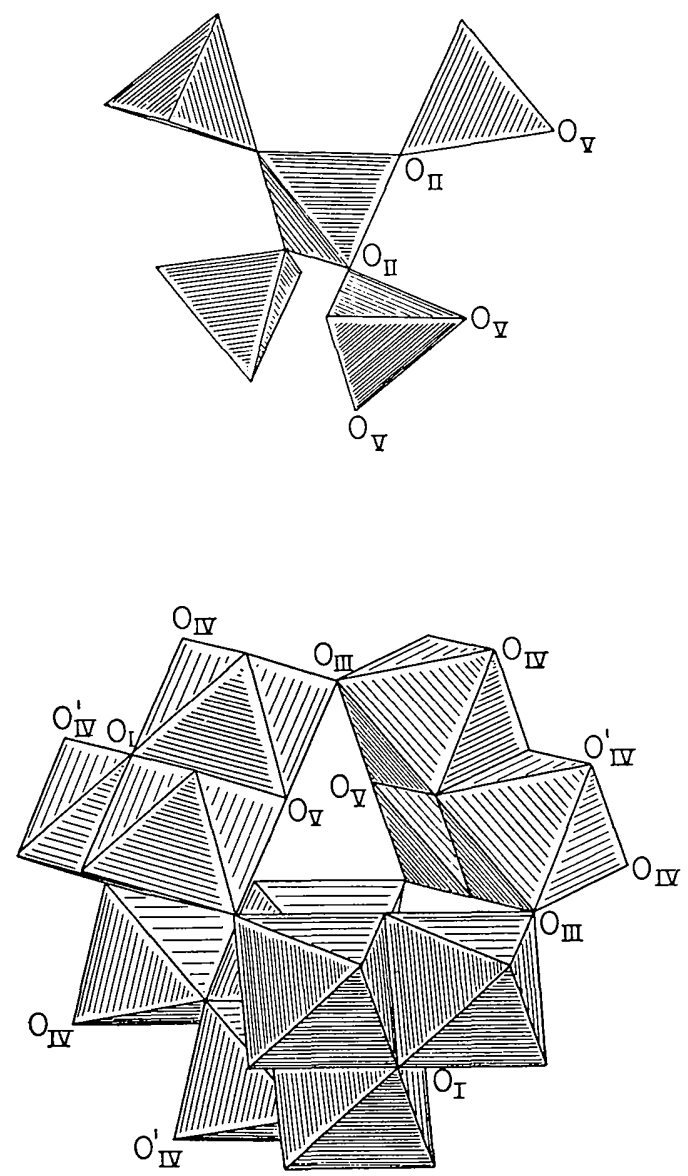

Fig. 1. Structural elements in zunyite: the $\mathrm{Si}_{5} \mathrm{O}_{16}$ group (above), and the group of linked $\mathrm{AlO}_{6}$ octahedra (below). 
distances for an examination of the shapes of the coordination polyhedra, for a verification of the isolation of silicon in the $\mathrm{Si}_{5} \mathrm{O}_{16}$ groups, and to provide a determination of the $\mathrm{Al}-\mathrm{O}$ distance for tetrahedrally coordinated aluminum.

\section{Experimental}

Perfect, clear tetrahedral crystals of zunyite, 0.2 to $0.6 \mathrm{~mm}$. in size, were obtained from a specimen of zunyite-guitermanite rock from the Zuñi Mine, near Silverton, Colorado. Zero layer Weissenberg photographs about [100] and [110] as rotation axes were obtained with Mo $K \alpha$ radiation. The reflections were recorded on multiple films interleaved with copper foil. From a crystal rotating about [100], 133 of the 163 possible $h k 0$ reflections were observed. A separate crystal (rotation axis [110]) provided $409 h h l$ reflections, of which 340 were strong enough to record. Intensities of the reflections were estimated visually by comparison with standard intensity scales, and were corrected for the Lorentz and polarization effects in the usual way. They were placed on an absolute scale by comparison with calculated intensities in the course of the refinement.

\section{Space group and cell dimensions}

Zunyite is isometric, crystallizes with tetrahedral habit, and shows Laue symmetry $\mathrm{O}_{h}$. The absence of all reflections having mixed indices and the presence of $h h l$ with $h$ and $l$ odd defines the space group as $T_{d}^{2}-F \overline{4} 3 m$. The size of the cell was measured by means of a rotation photograph of the Straumanis type with the crystal rotating about [100]. The result, $a_{0}=$ $13.87 \pm 0.01 \AA$ (based on $\lambda_{\mathrm{Cu} K \alpha_{1}}=1.5405 \AA$ ) differs from the value $13 \cdot 820 \pm 0.005$ obtained by Pauling, the difference being accounted for in part by the difference between the old and new wavelength scales.

Atomic positions for the structure proposed by Pauling (1933), hereafter called the trial structure, are given in Table 3 . The density $2 \cdot 87$ g.cm. ${ }^{-3}$ calculated from the contents and size of the unit cell is to be compared with experimental values (Pauling, 1933, p. 445 ) that range from $2 \cdot 87$ to 2.90 g.cm. ${ }^{-3}$.

\section{Verification and refinement of the structure}

Examination of the structure was made principally with the use of the $h k 0$ data, because of the centrosymmetry of the (100) projection. A preliminary comparison of calculated and observed $h k 0$ structure factors for the 43 reflections out to $\sin ^{2} \theta / \lambda^{2}=0.5$ provided a provisional temperature parameter $B=$ $0.6 \AA^{2}$, and resulted in a residual $R_{1}=\sum\left|F_{o}-F_{c}\right| / \Sigma\left|F_{o}\right|$ of $0 \cdot 33$. A Fourier synthesis of the (100) projection, carried out with signs calculated from the trial structure for the 43 reflections out to $\sin ^{2} \theta / \lambda^{2}=0.5$, reproduced all the general features of the trial structure and suggested several parameter changes. Based on the new parameters, a calculation of structure factors for all $163 h k 0$ reflections $\left(\sin ^{2} \theta / \lambda^{2}\right.$ out to 1.9 ) gave a residual $R_{1}$ of $0 \cdot 27$. Successive least-squares refinement of positional parameters, using a weighting system of the kind described for the $h h l$ data (below), then lowered $R_{1}$ to $0 \cdot 17$.

Atomic scattering factors for $\mathrm{Si}^{+4}, \mathrm{Al}^{+3}, \mathrm{Cl}^{-}$, and $\mathrm{F}^{-}$ were obtained from Berghuis et al. (1955). Scattering factors for $\mathrm{O}^{-2}$ were obtained by correcting the factors for $\mathrm{O}$, given by Berghuis et al. (1955), by the difference between values for $\mathrm{O}^{-2}$ and $\mathrm{O}$ from the Internationale Tabellen. The use of scattering factors appropriate to a purely ionic structure has no special justification, and was chosen from among the various alternatives simply because the electronegativities of the various atoms suggest that the bonds have on the average more nearly ionic rather than covalent character. An intermediate choice would be preferable, if a reliable basis for determining the amount of electron transfer were known. Electron counts on the final Fourier projections suggest that aluminum and silicon atoms (which are essentially indistinguishable) contain about 11 electrons, and the oxygen atoms about 9 , but these numbers are rather uncertain. On the refined difference maps no systematic electron-density discrepancies attributable to errors in the assumed scattering factors are recognized.

Calculations were carried out with the IBM 604, and Fourier syntheses were calculated by the ' $M$-card' method on the IBM 402. In the least-squares calculations, off-diagonal terms in the normal equation matrix were calculated because of overlap of the atoms $\mathrm{O}_{\mathrm{I}}, \mathrm{O}_{\mathrm{II}}$, and $\mathrm{O}_{\mathrm{IV}}$ in the (100) projection (Fig. 2). Although the overlap looks serious in the Fourier synthesis, the portion of the normal equation matrix for parameter shifts of the overlapping atoms was found on inclusion of all reflections to be

\begin{tabular}{|c|c|c|c|}
\hline & $\mathrm{O}_{\mathrm{I}}$ & $\mathrm{O}_{\text {II }}$ & $\mathrm{O}_{\mathrm{IV}}$ \\
\hline $\mathrm{O}_{\mathrm{I}}$ & $1 \cdot 00$ & $-0 \cdot 19$ & -0.68 \\
\hline $\mathrm{O}_{\mathrm{II}}$ & $-0 \cdot 20$ & $1 \cdot 00$ & 0.90 \\
\hline $\mathrm{O}_{\mathrm{IV}}$ & -0.33 & 0.42 & $1 \cdot 00$ \\
\hline
\end{tabular}

indicating resolution of the three parameter shifts adequate for a complete refinement using $h k 0$ data alone. (In writing the matrix, each normal equation has been multiplied by a separate factor so as to make the diagonal coefficients equal to $1 \cdot 00$, hence the matrix is not symmetric.)

A difference synthesis $\left(\varrho_{o}-\varrho_{c}\right)$ for the (100) projection, calculated with the results of the least-squares refinement, showed errors in the assumed thermal motions and indicated that different isotropic temperature parameters should be introduced for the different atoms. Least-squares calculation of the separate temperature parameter adjustments gave unsatisfactory predictions, requiring for the chlorine parameter a slight decrease in $B_{\mathrm{Cl}}$ whereas the difference map indicated a substantial increase in $B_{\mathrm{Cl}}$. 
The cause of this difficulty was not found, and refinement of the separate temperature parameters was therefore carried out by means of difference syntheses. This refinement reduced $R_{1}$ to $0 \cdot 123$. To the extent that significantly different temperature parameters for different atoms can be recognized in the (100) projection, the parameters obtained are

$$
\begin{array}{lc}
\mathrm{Si} \text { and } \mathrm{Al} & B=0 \cdot 2 \AA^{2} \\
\mathrm{Cl} & 0.9 \\
\mathrm{OH}\left(\mathrm{O}_{\mathrm{III}}, \mathrm{O}_{\text {IV }}\right) & 0 \cdot 6 \\
\text { O (others) } & 0.5
\end{array}
$$

A final least-squares refinement of positional parameters indicated only small shifts ( 0.001 or less) and

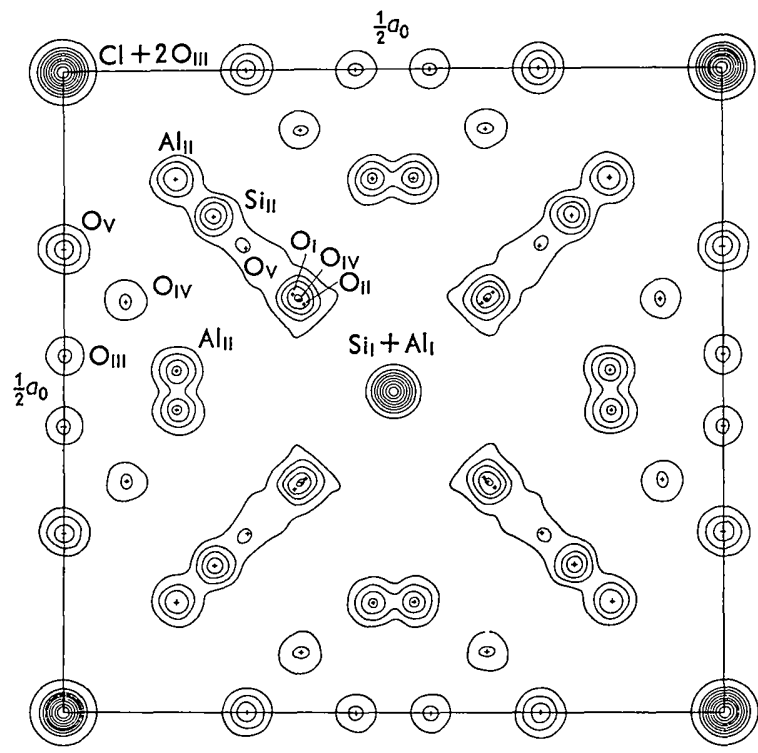

Fig. 2. Electron density in the (100) projection of zunyite. Contour interval $16 \cdot 3 \mathrm{e} . \AA^{-2}$. Final atomic position from leastsquares refinement are marked with crosses.

\section{Table 1. Zunyite, $h k 0$ reflections}

Unobserved reflections are starred, and the $F_{0}$ value given is half the minimum observable

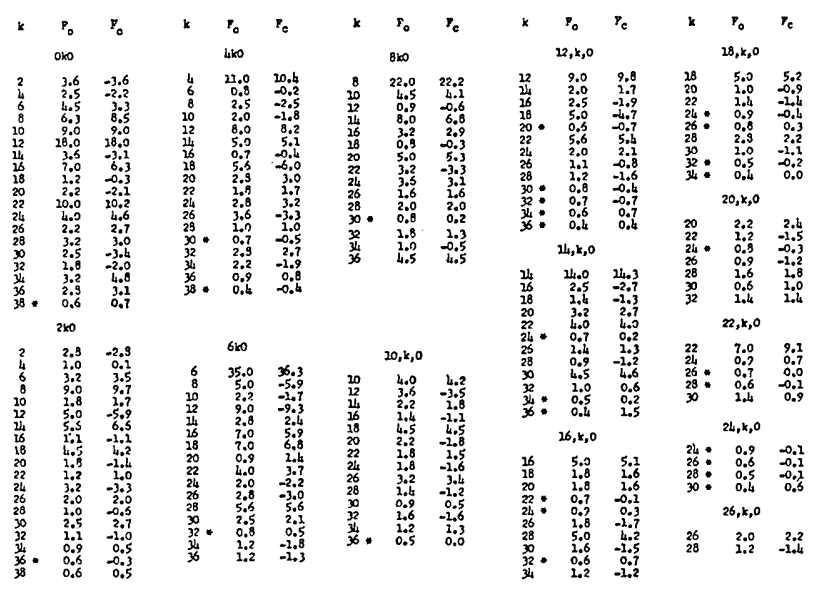

resulted in the value $0 \cdot 117$ for $R_{1}$. The Fourier synthesis based on signs calculated from the final structure is shown in Fig. 2. A comparison of observed structure factors with structure factors calculated from the final parameters is given in Table 1 . The structure factors can be converted to units of electrons per unit cell, as given by the formulae of the International Tables, by multiplying by the factor $17 \cdot 4$.

\section{Refinement with $h h l$ data}

There are several reasons for the desirability of studying the zunyite structure in other than the (100) projection: (1) inability to distinguish between $\mathrm{O}_{\mathrm{I}}$ and $\mathrm{O}_{\mathrm{II}}$ in the (100) projection, and relatively large uncertainty in the parameter values derived for these atoms; (2) some uncertainty in the $x$ parameter for $\mathrm{O}_{\mathrm{IV}}$, due to overlap with $\mathrm{O}_{\mathrm{I}}$ and $\mathrm{O}_{\mathrm{II}} ;(3)$ inability to make a reasonable statistical estimate of the accuracy of the $z_{6}$ parameter without going to a second order theory; (4) inability to distinguish the position $(0,0,0)$, where a vacancy is assumed in the trial structure, from $\left(\frac{1}{2}, \frac{1}{2}, \frac{1}{2}\right)$, where the chlorine atom is placed; (5) inability to distinguish the position at $\left(\frac{1}{4}, \frac{1}{4}, \frac{1}{4}\right)$ from the position at $\left(\frac{3}{4}, \frac{3}{4}, \frac{3}{4}\right)$, and to demonstrate that the latter is actually occupied by an aluminum atom; (6) desirability of an independent refinement of the atomic positions, to compare with the results of a statistical estimation of parameter standard deviations.

An independent refinement of the structure was therefore carried out with $h h l$ data. The $(1 \overline{1} 0)$ projection is non-centrosymmetric, so that calculation procedures for the $h h l$ reflections are considerably longer than for the $h k 0$ reflections. Comparison of observed $h h l$ intensities with intensities calculated from the final atomic positions of the $h k 0$ refinement showed general agreement but resulted in a residual $R_{1}^{\prime}=\Sigma\left|I_{o}-I_{c}\right| / \Sigma I_{o}$ of $0 \cdot 27$, corresponding to $R_{1}=0 \cdot 19$ (obtained by extraction of square roots in the course of phase calculation for Fourier synthesis). The much greater discrepancy for $h h l$ data than for the final $h k 0$ data proved to be due mainly to a large discrepancy between the temperature parameters appropriate to the two sets of data. The $h h l$ data require values of $B$ for each of the various atoms (as shown by calculation of $h h l$ difference maps) about $0 \cdot 3 \AA^{2}$ greater than obtained in the $h k 0$ refinement. The discrepancy corresponds approximately to a doubling of the absolute temperature, and therefore cannot be attributed to any possible temperature effect. It must be the result of a systematic error between the two sets of data.

Differences in absorption for the two crystals used are calculated to be an order of magnitude too small to account for the observed discrepancy.

Because of the normal degradation of intensity with Bragg angle, the temperature parameter discrepancy can be simulated by a discrepancy in the contrast scales gamma (Mees, 1954) of films used for recording 
the two sets of data or for preparing the intensity comparison photographs used for visual estimation of the intensities. Although it is not possible to prove readily that this is the source of the discrepancy between the $h k 0$ and $h h l$ data, microphotometer measurements of the intensity comparison photographs show that a difference in gamma of sufficient size and in the right direction to account for the discrepancies is present. The measurements also indicate that the temperature parameter error probably lies in the $h k 0$ rather than in the $h h l$ data.

It can be shown that an error in contrast $\Delta \lambda$, where

$$
\gamma=d D / d \log I_{o}
$$

and $D$ is the photographic density, defined as the logarithm of the reciprocal of the fractional transmissivity for light, results in an error in the temperature parameter given approximately by

$$
\Delta B / B=\frac{\Delta \gamma}{\gamma} \cdot \frac{B+\Gamma}{B} .
$$

Here $\Gamma$ is the exponent in the (assumed) exponential decrease of the atomic scattering factors with $\sin ^{2} \theta / \lambda^{2}$ :

$$
f(\theta)=f_{0} \exp \left(-\Gamma \sin ^{2} \theta / \lambda^{2}\right),
$$

corresponding to a Gaussian electron density

$$
\varrho(r)=\varrho_{0} \exp \left(-\left(4 \pi^{2} / \Gamma\right) r^{2}\right)
$$

where $r$ is the distance from the center of the atom with scattering factor $f(\theta)$. Thus it is seen that for small thermal motion $(B<\Gamma)$ the fractional error in $B$ can be much larger than the fractional error in $\gamma$. For zunyite, a discrepancy of $15 \%$ in $\gamma$ gives rise to a discrepancy of more than $100 \%$ in $B$. For organic compounds at room temperature, for which $B$ is generally somewhat greater than $\Gamma$, the effect of an error in $\gamma$ is less serious. Nevertheless, it is evident that the contrast must be carefully controlled if meaningful values of $B$ are to be derived from photographic intensity measurement.

Three least-squares adjustments of the positional parameters were carried out with the $h h l$ data. The weighting system used gives a weight of 1 to weak reflections, $\frac{1}{3}$ to unobserved reflections, and weights proportional to $1 / F^{2}$ for intermediate and strong reflections $\left(I_{o} \geq 30\right)$. A second refinement, using a weighting system differing from the first only in the choice of the upper limit of unit weight $\left(I_{o} \geq 90\right)$, gave atomic positions that do not differ significantly (see Kamb, 1960) from the positions obtained using the first weighting system. The atomic positions derived in the $h h l$ refinement differ significantly from those of the $h k 0$ refinement only in the parameter $z_{4}$, the difference corresponding to a displacement of $0.03 \AA$ in the position of $\mathrm{O}_{\mathrm{III}}$. Final positional parameters were chosen as the average of the results of the $h k 0$ and $h h l$ refinements and are given in Table 3. A Fourier synthesis of the asymmetric unit of the projection on
(110), made with phase angles calculated from positions determined in the $h h l$ refinement, is given in Fig. 3, and the symmetry relations of the asymmetric unit to the projection of the entire cell are shown in Fig. 4.

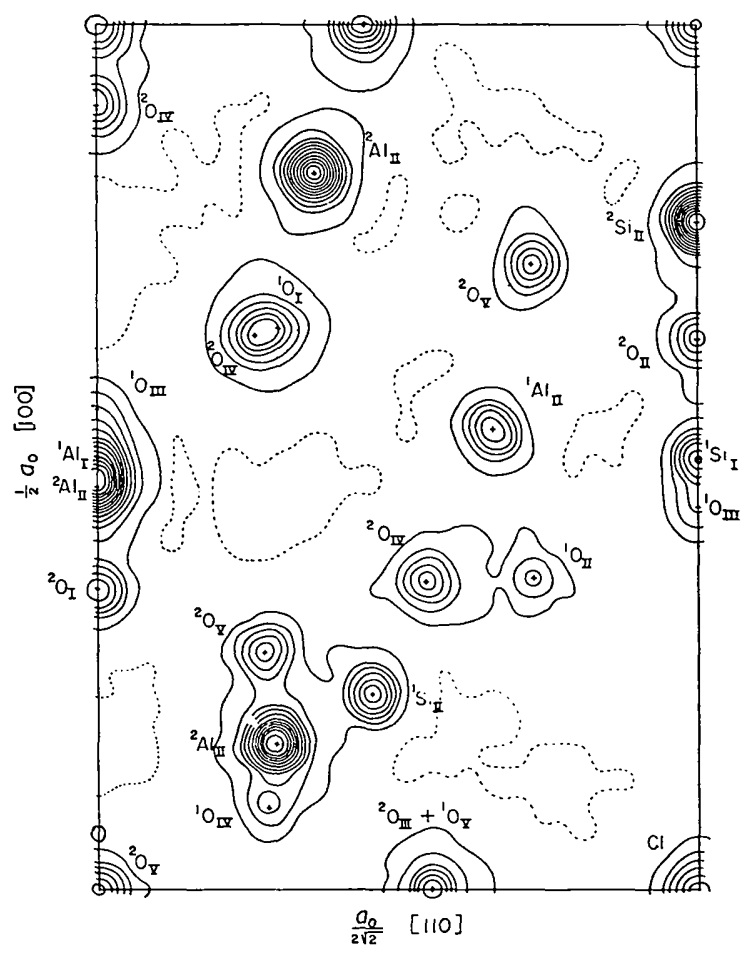

Fig. 3. Electron density in the asymmetric unit of the (I $\overline{1} 0)$ projection of zunyite. Contour interfal $23 \cdot 0$ e. $\AA .^{-2}$. Zero contour dashed. Final atomic positions marked with crosses. Superscripts designate half the number of symmetryequivalent atoms that project from the entire cell to a given position in the projection.

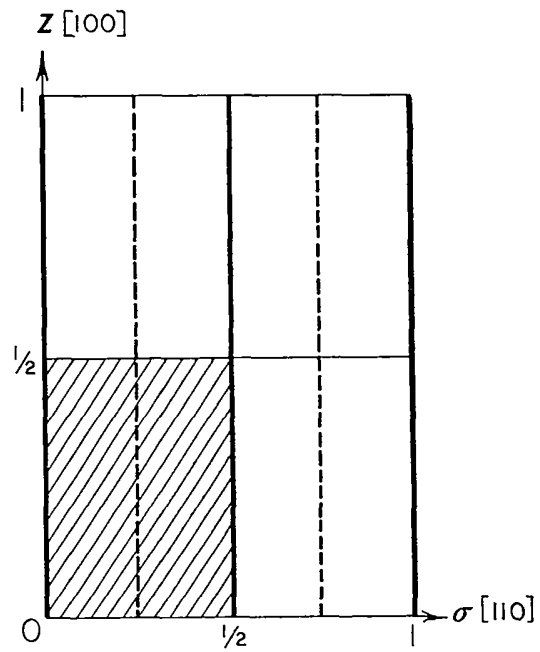

Fig. 4. Symmetry of the (1) 0 ) projection of zunyite. $\sigma$ is half the (001) face diagonal of the unit cell $(\sigma=x+y)$. The asymmetric unit (Fig. 3) is shaded. 
Table 2. Zunyite, hhk reflections

Unobserved reflections are starred, and the $I_{o}$ value given is half the minimum observable.

The $I_{o}$ values have been corrected for Lorentz and polarization effects. Note that $I_{c}$ differs from $A^{2}+B^{2}$ by a scaling factor
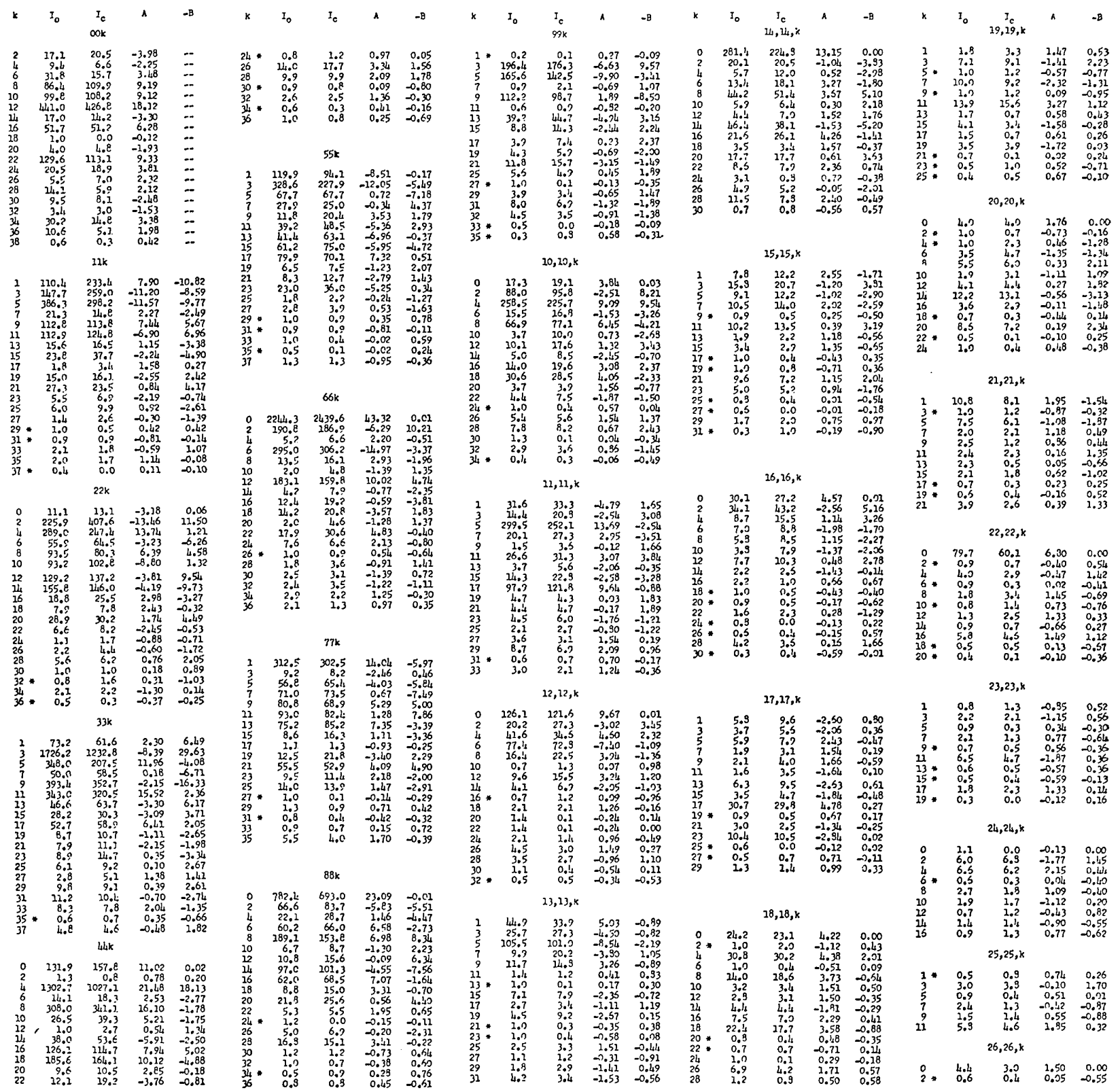

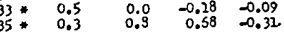
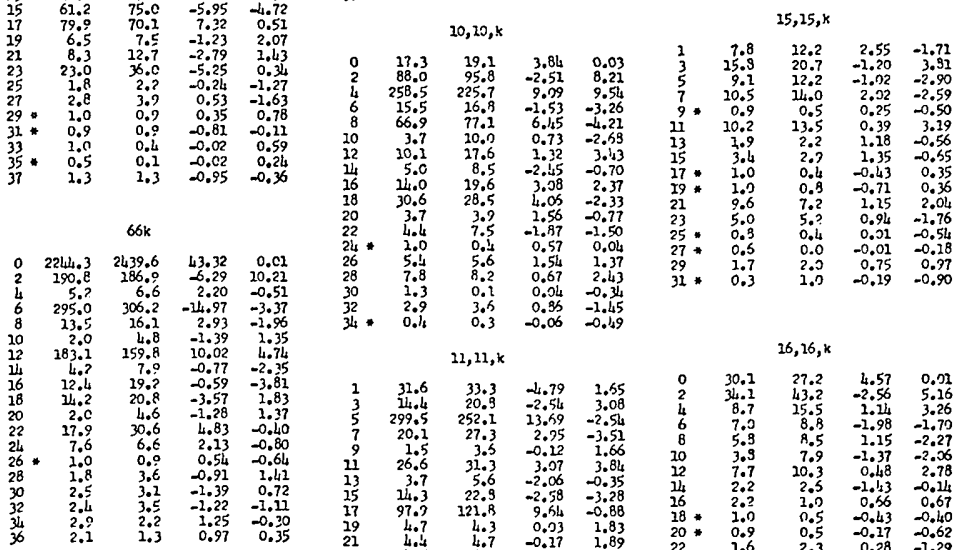

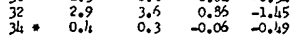
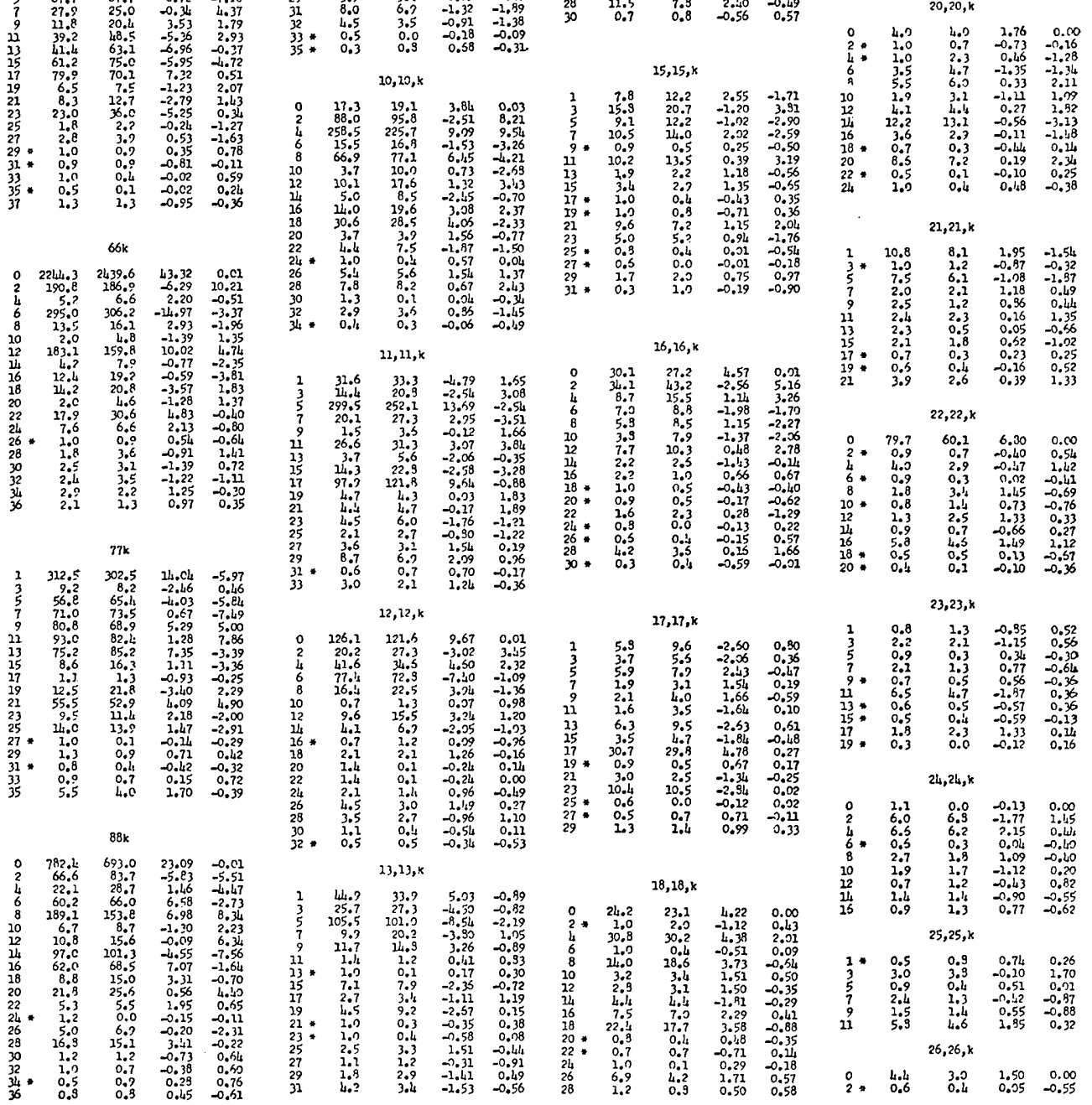

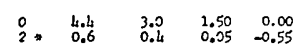

The final residual is $R_{1}^{\prime}=0 \cdot 19$, corresponding approximately to a 'reliability factor' $R_{1}$ of 0.115 . Observed $h h l$ intensities $I_{0}$ (corrected for Lorentz and polarization effects), and intensities $I_{c}$ calculated from the final positions of the $h h l$ refinement, are given in Table 2. Values of $A$ and $B$ are stated in arbitrary units, which can be converted to electrons per unit cell by multiplying by the factor $16 \cdot 0$. The values of $I_{c}$ can be converted to the square of these units by multiplying by the factor 197 .

\section{Accuracy of atomic positions}

A detailed study of the accuracy of atomic positions in the zunyite structure is described in a separate paper (Kamb, 1960). To be precise, the estimated accuracy of interatomic distances would have to be calculated separately for each pair of atoms from the data in Table 1 of that paper. Without doing this in detail, an upper limit of $0.02 \AA$ can be placed on the standard deviation for any cation-oxygen distance, 
and $0.03 \AA$ for any oxygen-oxygen distance. Most cation-oxygen distances, however, have an accuracy (expressed as estimated standard deviation) close to $\pm 0.01 \AA$, and most oxygen-oxygen distances close to $\pm 0.02 \AA$. An upper limit of $\pm 1.3^{\circ}$ is estimated for the bond-angle accuracy.

The most important distances in the structure are the $\mathrm{Si}-\mathrm{O}$ distances, and the $\mathrm{Al}-\mathrm{O}$ distance for the tetrahedrally coordinated aluminum atoms. From the data given in Table 1 of Kamb (1960) one can estimate

$$
\begin{array}{ll}
\mathrm{Si}-\mathrm{O} \text { (average distance) } & =1 \cdot 64 \pm 0.01 \AA \\
\mathrm{Al}-\mathrm{O}_{\text {I }} \text { (tetrahedral) } & =1.80 \pm 0.016 \AA
\end{array}
$$

\section{Discussion of the structure}

Interatomic distances calculated from the final atomic coordinates (Table 3) are given in Table 4, with corresponding distances in the trial structure for comparison. The refined structure differs from the trial structure in the following ways: (1) enlargement of the $\mathrm{SiO}_{4}$ tetrahedra; (2) enlargement of the $\mathrm{AlO}_{4}$ tetrahedron; (3) increased separation of aluminum atoms in octahedra sharing edges; (4) distortion of the $\mathrm{AlO}_{6}$ octahedra, with pronounced shortening of shared edges; (5) decrease in the $\mathrm{Cl}-\mathrm{O}_{\text {III }}$ distance.

\begin{tabular}{|c|c|c|c|c|}
\hline Atom & $\begin{array}{c}\text { Posi- } \\
\text { tion }\end{array}$ & $\begin{array}{l}\text { Para- } \\
\text { meter }\end{array}$ & $\begin{array}{l}\text { Trial } \\
\text { value }\end{array}$ & $\begin{array}{l}\text { Final } \\
\text { value }\end{array}$ \\
\hline $16 \mathrm{Si}_{\mathrm{II}}$ & $e$ & $x_{1}$ & $0 \cdot 117$ & 0.1143 \\
\hline $16 \mathrm{O}_{\mathrm{I}}$ & $e$ & $x_{2}$ & -0.177 & $-0 \cdot 1750$ \\
\hline $16 \mathrm{O}_{\mathrm{II}}$ & e & $x_{3}$ & $0 \cdot 184$ & $0 \cdot 1818$ \\
\hline $24 \mathrm{O}_{\text {III }}$ & $f$ & $z_{4}$ & $0 \cdot 273$ & $0 \cdot 2780$ \\
\hline \multirow[t]{2}{*}{$48 \mathrm{O}_{\mathrm{IV}}$} & $h$ & $x_{5}$ & $0 \cdot 181$ & 0.1793 \\
\hline & & $z_{5}$ & 0.545 & 0.5466 \\
\hline \multirow[t]{2}{*}{$48 \mathrm{O}_{\mathrm{V}}$} & $h$ & $x_{6}$ & $0 \cdot 136$ & $0 \cdot 1385$ \\
\hline & & $z_{6}$ & 0.006 & $0 \cdot 0003$ \\
\hline \multirow[t]{2}{*}{$48 \mathrm{Al}_{\mathrm{II}}$} & $h$ & $x_{7}$ & 0.089 & 0.0853 \\
\hline & & $z_{7}$ & $-0 \cdot 228$ & -0.2333 \\
\hline $4 \mathrm{Cl}$ & $b$ & - & - & - \\
\hline $4 \mathrm{Si}_{\mathrm{I}}$ & $c$ & - & 一 & - \\
\hline $4 \mathrm{Al}_{\mathrm{I}}$ & $d$ & - & - & 一 \\
\hline
\end{tabular}

Table 3. Atomic coordinates

Position Coordinates of equivalent atoms$$
\begin{gathered}
\left(0,0,0 ; 0, \frac{1}{2}, \frac{1}{2} ; \frac{1}{2}, 0, \frac{1}{2} ; \frac{1}{2}, \frac{1}{2}, 0\right)+ \\
48 h \quad x, x, z ; z, x, x ; x, z, x ; \bar{x}, x, \bar{z} ; \bar{z}, x, \bar{x} ; \bar{x}, z, \bar{x}
\end{gathered}
$$$$
x, \bar{x}, \bar{z} ; z, \bar{x}, \bar{x} ; x, \bar{z}, \bar{x} ; \bar{x}, \bar{x}, z ; \bar{z}, \bar{x}, x ; \bar{x}, \bar{z}, x
$$$$
24 f \quad x, 0,0 ; 0, x, 0 ; 0,0, x ; \bar{x}, 0,0 ; 0, \bar{x}, 0 ; 0,0, \bar{x}
$$$$
16 e \quad x, x, x ; x, \bar{x}, \bar{x} ; \bar{x}, x, \bar{x} ; \bar{x}, \bar{x}, x
$$$$
4 d \quad \frac{3}{4}, \frac{3}{4}, \frac{3}{4}
$$$$
4 c \quad \frac{1}{1}, \frac{1}{4} \text {. }
$$$$
4 b \quad \frac{1}{2}, \frac{1}{2}, \frac{1}{2}
$$

Enlargement of the $\mathrm{SiO}_{4}$ tetrahedra is probably due to partial replacement of silicon by aluminum. An Si-O distance of $1 \cdot 64 \pm 0.01 \AA$ corresponds to random replacement of $1 \cdot 1 \pm 0 \cdot 3$ out of every five silicon atoms by an aluminum atom, on the basis of Smith's (1954) discussion of interatomic distances in silicates. The chemical analyses (Pauling, 1933) indicate a maximum
Table 4. Interatomic distances and bond angles

Tetrahedra

$\begin{array}{lll}\text { Atoms } & \text { Trial } & \text { Final } \\ \mathrm{Si}_{\mathrm{I}}-\mathrm{O}_{\mathrm{II}} & 1.59 \AA & 1.64 \AA \\ \mathrm{Si}_{\mathrm{II}}-\mathrm{O}_{\mathrm{II}} & 1.59 & 1.62_{5} \\ \mathrm{Si}_{\mathrm{II}}-\mathrm{O}_{\mathrm{V}} & 1.59 & 1.65 \\ \mathrm{Al}_{\mathrm{I}}-\mathrm{O}_{\mathrm{I}} & 1 \cdot 74 & 1.80\end{array}$

Octahedra

$\begin{array}{lll}\text { Atoms } & \text { Trial } & \text { Final } \\ \mathrm{Al}_{\text {II }}-\mathrm{O}_{\mathrm{I}} & 1.86 \AA & 1.93 \AA \\ \mathrm{Al}_{\mathrm{II}}-\mathrm{O}_{\mathrm{III}} & 1.85 & 1.78 \\ \mathrm{Al}_{\mathrm{II}}-\mathrm{O}_{\mathrm{IV}} & 1.89 & 1.86 \\ \mathrm{Al}_{\mathrm{II}}-\mathrm{O}_{\mathrm{V}} & 1.93 & 1.92\end{array}$

\begin{tabular}{|c|c|c|}
\hline Atoms & Trial & Final \\
\hline $\begin{array}{l}\mathrm{Cl}-\mathrm{O}_{\text {III }} \\
\mathrm{Cl}-\mathrm{O}_{\text {IV }}\end{array}$ & $\begin{array}{l}3 \cdot 14 \AA \\
3 \cdot 59\end{array}$ & $\begin{array}{l}3 \cdot 08 \\
3 \cdot 58\end{array}$ \\
\hline
\end{tabular}

Chlorine

Tetrahedron edges:

$\begin{array}{lcc}\text { Atoms } & \text { Trial } & \text { Final } \\ \mathrm{O}_{\mathrm{II}}-\mathrm{O}_{\mathrm{II}} & 2 \cdot 60 \AA & 2 \cdot 67 \AA \\ \mathrm{O}_{\mathrm{II}}-\mathrm{O}_{\mathrm{V}} & 2 \cdot 60 & 2 \cdot 66 \\ \mathrm{O}_{\mathrm{V}}-\mathrm{O}_{\mathrm{V}} & 2 \cdot 60 & 2 \cdot 72 \\ \mathrm{O}_{\mathrm{I}}-\mathrm{O}_{\mathrm{I}} & 2 \cdot 84 & 2 \cdot 94\end{array}$

Octahedron edges

\begin{tabular}{|c|c|c|}
\hline Atoms & Trial & Final \\
\hline $\mathrm{O}_{\mathrm{I}}-\mathrm{O}_{\mathrm{IV}}$ & $2.68 \AA$ & $2 \cdot 69 \AA$ \\
\hline $\mathrm{O}_{\mathrm{III}}-\mathrm{O}_{\mathrm{IV}}$ & $2 \cdot 67$ & $2 \cdot 64$ \\
\hline $\mathrm{O}_{\mathrm{III}}-\mathrm{O}_{\mathrm{V}}$ & $2 \cdot 67$ & $2 \cdot 73$ \\
\hline $\mathrm{O}_{\mathrm{IV}}-\mathrm{O}_{\mathrm{IV}}$ & $2 \cdot 67$ & $2 \cdot 60$ \\
\hline $\mathrm{O}_{\mathrm{IV}}-\mathrm{O}_{\mathrm{V}}$ & $2 \cdot 64$ & $2 \cdot 67$ \\
\hline $\mathrm{O}_{\mathrm{V}}-\mathrm{O}_{\mathrm{V}}$ & $2 \cdot 84$ & $2 \cdot 72$ \\
\hline Average & $2 \cdot 68$ & $2 \cdot 67_{5}$ \\
\hline
\end{tabular}
Unshared

Shared

$\begin{array}{lrr}\text { Atoms } & \text { Trial } & \text { Final } \\ \mathrm{O}_{\mathrm{I}}-\mathrm{O}_{\mathrm{V}} & 2 \cdot 64 \AA & 2 \cdot 53 \AA\end{array}$

'Non-bonded', contact

$\begin{array}{lrr}\text { Atoms } & \text { Trial } & \text { Final } \\ \mathrm{O}_{\text {IV }}-\mathrm{O}_{\text {IV }}^{\prime} & 2 \cdot 71 \AA & 2 \cdot 77 \AA\end{array}$

\begin{tabular}{|c|c|c|}
\hline Atoms & Trial & Final \\
\hline $\begin{array}{l}\mathrm{Si}_{\mathrm{I}}-\mathrm{Si}_{\mathrm{II}} \\
\mathrm{Si}_{\mathrm{II}}-\mathrm{Al}_{\mathrm{II}} \\
\mathrm{Al}_{\mathrm{II}}-\mathrm{Al}_{\mathrm{II}}\end{array}$ & $\begin{array}{l}3 \cdot 18 \AA \\
3 \cdot 27\end{array}$ & $\begin{array}{l}3 \cdot 26 \AA \\
3 \cdot 24\end{array}$ \\
\hline Sharing edge & $2 \cdot 72$ & $2 \cdot 90$ \\
\hline Sharing O & $3 \cdot 49$ & $3 \cdot 34$ \\
\hline Sharing $\mathrm{O}_{\mathrm{IV}}$ corner & 3.58 & $3 \cdot 56$ \\
\hline $\begin{array}{l}\mathrm{Al}_{\mathrm{I}}-\mathrm{Al}_{\mathrm{II}} \\
\mathrm{CI}-\mathrm{Al}\end{array}$ & $\begin{array}{l}3 \cdot 17 \\
4 \cdot 16\end{array}$ & $\begin{array}{l}3 \cdot 24 \\
4 \cdot 06\end{array}$ \\
\hline
\end{tabular}

Cation-Cation

Angles

$\begin{array}{lll}\text { Atoms } & \text { Trial } & \text { Final } \\ \mathrm{Al}_{\text {II }}-\mathrm{O}_{\mathrm{III}}-\mathrm{Al}_{\mathrm{II}} & 142^{\circ} & 139 \cdot 2^{\circ} \\ \mathrm{Al}_{\mathrm{II}}-\mathrm{O}_{\mathrm{IV}}-\mathrm{Al} & 142 & 146 \cdot 6\end{array}$

of 0.4 out of 5 silicon atoms replaced. Without further information on the reliability of the chemical analyses, it is not possible to comment on this discrepancy.

The Al-O distance of $1 \cdot 80 \pm 0 \cdot 016 \AA$ for tetrahedrally 
coordinated aluminum is to be compared with the value $1.78 \pm 0.02 \AA$ accepted by Smith (1954).

The increased size of the $\mathrm{SiO}_{4}$ tetrahedra causes increased $\mathrm{O}-\mathrm{O}$ distances in the $\mathrm{Si}_{5} \mathrm{O}_{16}$ group. The $\mathrm{O}_{\mathrm{v}}-\mathrm{O}_{\mathrm{v}}$ distances increases by an amount $(0.06 \AA)$

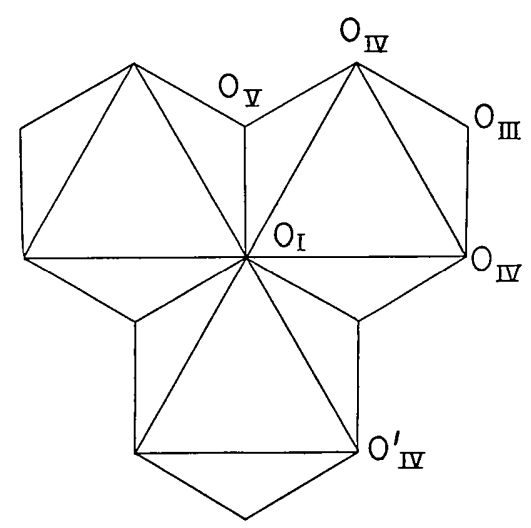

Fig. 5. The $\mathrm{Al}_{3} \mathrm{O}_{13}$ group in zunyite, viewed along a 3-fold axis. 'Non-bonded', oxygen atoms form the pairs $\mathrm{O}_{\mathrm{IV}}-\mathrm{O}_{\mathrm{TV}}^{\prime}$.

significantly greater than other $\mathrm{O}-\mathrm{O}$ distances in the group, producing a distortion in the outer four tetrahedra of the group, by enlarging the outward-directed faces of these tetrahedra. This distortion is caused by the effects of repulsion between the aluminum atoms.

The effects of this repulsion are probably the most striking features which distinguish the trial and final structures. The $\mathrm{Al}_{\mathrm{II}}$ atoms occur in groups of three at the centers of three octahedral groups of oxygen atoms, sharing edges to form an $\mathrm{Al}_{3} \mathrm{O}_{13}$ group (Fig. 5). In the trial structure, the octahedra are nearly regular in shape, and the aluminum are atoms located nearly centrally in them, the distance $\mathrm{Al}_{\mathrm{II}}-\mathrm{O}_{\mathrm{V}}$ being elongated somewhat by the pulling in of the oxygen atoms toward silicon. In the refined structure, the aluminum atoms increase in separation by $0.18 \AA$, and the octahedral groups become markedly distorted. The shared edges contract to a length of $2.53 \AA$. There is a general rearrangement of the other $\mathrm{O}-\mathrm{O}$ distances, but the average length of the unshared edges does not change significantly. The increased separation of $\mathrm{Al}_{I I}$ atoms is facilitated by the decrease in the $\mathrm{O}_{\mathrm{v}}-\mathrm{O}_{\mathrm{v}}$ octahedral edge length, the distance $\mathrm{Al}_{I I}-\mathrm{O}_{\mathrm{V}}$ remaining practically unchanged. The $\mathrm{Al}_{\text {II }}$ atoms move away from the centers of the distorted octahedral groups, and toward the $\mathrm{O}_{\text {IIr }}$ atoms. This effect is strikingly shown in the (110) projection of the structure (Fig. 3), in which the $\mathrm{Al}_{\text {II }}$ peak is noticeably offset from the geometrical center of the projected $\mathrm{O}_{\mathrm{I}}-\mathrm{O}_{\mathrm{V}}-\mathrm{O}_{\mathrm{III}}-{ }^{2} \mathrm{O}_{\mathrm{IV}}$ octahedron. The average $\mathrm{Al}-\mathrm{O}$ distance, $1.88 \AA$, remains in close agreement with the radius sum, $1.90 \AA$ (Pauling, 1939).

The contraction of the shared edges to $2.53 \AA$ is in harmony with shared-edge lengths in aluminum octahedra found in other structures: $2.50 \AA$ in diaspore (Ewing, 1935) and $2 \cdot 49 \pm 0.03 \AA$ (average value) in gibbsite (Megaw, 1934). The usual comparison with corundum (Strukturbericht, 1931, p. 242), for which a value $2 \cdot 49 \AA$ is quoted, does not seem entirely justified, inasmuch as the value $2.49 \AA$ refers to the edge of a face shared between two octahedra, while the lengths of single edges shared between octahedra is $2 \cdot 61 \AA$. It would be desirable to compare the shared-edge length with values found in the chemically related structures of topaz, andalusite, sillimanite, and $\mathrm{ky}-$ anite, but the early determinations of these structures have not been systematically refined. The available values (Strukturbericht, 1937, pp. 110-117) are scattered: $2 \cdot 59,2 \cdot 83$ and $2 \cdot 47 \AA$.

\section{Location of protons in the structure}

Of the 38 oxygen atoms in the zunyite structural unit, 18 must have protons attached in order to satisfy the electrostatic valence rule, or must be substituted by fluorine (Pauling, 1933). It has proved impossible to locate these protons by X-ray means, but the interatomic distance and bond angle information give definite indication of the scheme of proton arrangement in the crystal.

Pauling's reasoning (1933) shows that the protons are associated with the $\mathrm{O}_{I I I}$ and $\mathrm{O}_{\mathrm{IV}}$ atoms. We first consider $\mathrm{O}_{\text {III. }}$. Comparison of the observed $\mathrm{Cl}-\mathrm{O}_{\text {III }}$ distance of $3.08 \AA$ with the sum of the $\mathrm{Cl}$ and $\mathrm{O}$ crystal radii, $3 \cdot 21 \AA$, indicates that the proton on $\mathrm{O}_{\mathrm{III}}$ forms a hydrogen bond with chlorine. In $\mathrm{FeCl}_{2} .4 \mathrm{H}_{2} \mathrm{O}$, Penfold \& Grigor (in press) report that oxygen-chlorine distances for which the bond angles allow hydrogen bonding range from $3.07 \AA$ to $3.45 \AA$, and Harker (1936) found $\mathrm{OH} \cdots \mathrm{Cl}$ distances of $3.05 \AA$ in $\mathrm{CuCl}_{2} .2 \mathrm{H}_{2} \mathrm{O}$ and $3.05 \AA$ in $\mathrm{K}_{2} \mathrm{CuCl}_{4} .2 \mathrm{H}_{2} \mathrm{O}$. From Wells' (1949) data for atacamite, $\mathrm{Cu}_{2} \mathrm{Cl}(\mathrm{OH})_{3}, \mathrm{I}$ calculate $\mathrm{OH} \cdots \mathrm{Cl}$ distances of $3.07 \AA$ (for $\mathrm{OH}_{\mathrm{II}}$ ) and $2 \cdot 85 \AA$ (for $\mathrm{OH}_{\mathrm{I}}$ ), all other oxygen-chlorine distances being greater than $3.20 \AA$. The distance $2.85 \AA$ is suspect, and corresponds to an oxygen atom for which the $y$ parameter was considered uncertain by Wells (1949). The water molecules in $\mathrm{MgCl}_{2} .6 \mathrm{H}_{2} \mathrm{O}$ (Andress \& Gundermann, 1934) are considered, on the basis of distortion of the coordination polyhedra about $\mathrm{Mg}$, to form hydrogen bonds with chlorine, but the shortest oxygen-chlorine distances reported are $3 \cdot 21 \AA$. This lack of indication of hydrogen-bonding may be attributable to the large $\mathrm{Cl}-\mathrm{O}-\mathrm{Cl}$ angle of about $155^{\circ}$ at the water molecules (Donohue's survey (1952) suggests that for $\mathrm{N}-\mathrm{H} \cdots \mathrm{O}$ bonds a deviation of the acceptor oxygen by $40^{\circ}$ from collinearity with the $\mathrm{N}-\mathrm{H}$ group increases the $\mathrm{N}-\mathrm{H} \cdots \mathrm{O}$ bond length by $0 \cdot 2 \AA$ or more). A similar situation apparently exists in $\mathrm{Cd}(\mathrm{OH}) \mathrm{Cl}$ (Hoard \& Grenko, 1934), where each OH group bonds to three equidistant $\mathrm{Cl}$ - ions, the proton deviating by $41^{\circ}$ from collinearity with the $\mathrm{O}-\mathrm{Cl}$ pairs, and the oxygen-chlorine distance being $3.22 \AA$. Recently Yoon \& Carpenter (1959) have found an $\mathrm{OH} \cdots \mathrm{Cl}$ distance of $2 \cdot 95 \pm 0.01 \AA$ in $\mathrm{HCl} . \mathrm{H}_{2} \mathrm{O}$, and 
they refer to $\mathrm{OH} \cdots \mathrm{Cl}$ distances of $2.99 \AA, 2.99 \AA$, and $2.91 \AA$ in organic chlorides.

The clear indication of hydrogen-bonding between $\mathrm{OH}$ and $\mathrm{Cl}$ is in contradiction to a statement by Wells $(1950$, p. 424). The observed range of decrease of the oxygen-chlorine distance from the crystal radii sum, from no shortening to $0 \cdot 30 \AA$ or (questionably) $0 \cdot 36 \AA$ shortening, compares with the shortening range zero to $0.30 \AA$ for $\mathrm{O}-\mathrm{H} \cdots \mathrm{O}$ hydrogen bonds (Donohue, 1952; an instance of shortening by $0.40 \AA$ has been found by Takei (1957)). It is to be expected that the same factors-electronegativities of nearby atoms, and degree of collinearity of the proton with donor and acceptor atoms, in addition to steric factors-are responsible for the range of bond distances observed for both types of bond. To the extent that the strengths of $\mathrm{H} \cdots \mathrm{O}$ and $\mathrm{H} \cdots \mathrm{Cl}$ bonds are measured by the covalent bond numbers associated with these bonds, one may expect, as suggested by Pauling (private communication), that for an $\mathrm{O}-\mathrm{H} \cdots \mathrm{Cl}$ bond of the same strength as an $\mathrm{O}-\mathrm{H} \cdots \mathrm{O}$ bond the $\mathrm{O}-\mathrm{Cl}$ distance will be greater than the $\mathrm{O}-\mathrm{O}$ distance by the difference between the $\mathrm{H}-\mathrm{Cl}$ distance in $\mathrm{HCl}$ and the $\mathrm{H}-\mathrm{O}$ distance in $\mathrm{H}_{2} \mathrm{O}$ (vapor), that is, $0 \cdot 31 \AA$. Thus the hydrogen bonds of intermediate strength in ice correspond to $\mathrm{O}-\mathrm{H} \cdots \mathrm{Cl}$ bonds of length $3.07 \AA$, close to the observed distance in zunyite, and the expected range of $\mathrm{O}-\mathrm{H} \cdots \mathrm{Cl}$ bond lengths is from about $2 \cdot 85 \AA$ (strong H-bonds) to about $3 \cdot 2 \AA$ (weak $\mathrm{H}$-bonds), in satisfactory agreement with observation. From this same point of view we may compare the $\mathrm{OH} \cdots \mathrm{Cl}$ distances in $\mathrm{HCl} . \mathrm{H}_{2} \mathrm{O}$ and in zunyite by noting that in $\mathrm{HCl} . \mathrm{H}_{2} \mathrm{O}$, the coordination of three $\mathrm{H}_{3} \mathrm{O}^{+}$ions in nearly tetrahedral relative orientation about each $\mathrm{Cl}^{-}$ ion allows one electron pair of the $\mathrm{Cl}^{-}$valence shell to be involved in forming each of the hydrogen bonds, whereas in zunyite the octahedral coordination of $\mathrm{Cl}$ by $\mathrm{O}_{\text {III }}$ atoms allows only $\frac{2}{3}$ electron pair to be associated with each $\mathrm{OH} \cdots \mathrm{Cl}$ bond. Accordingly the expected increase in bond length in zunyite is $0.6 \log \frac{3}{2}$ or $0.11 \AA$, close to the observed value $0.13 \AA$.

It is difficult, however, to judge independently to what extent the $\mathrm{OH} \cdots \mathrm{Cl}$ distance in zunyite is determined by the 'equilibrium' H-bond distance and to what extent by steric factors. That there are forces pulling the $\mathrm{O}_{\mathrm{II}}$ atom in toward $\mathrm{Cl}$ is shown by the short observed value of the $\mathrm{O}_{\mathrm{III}}-\mathrm{O}_{\text {IV }}$ distance, which is compressed by such a motion, and the long $\mathrm{O}_{\mathrm{III}}-\mathrm{O}_{\mathrm{V}}$ distance, which is simultaneously extended. While these distances indicate a structural restriction on the approach of $\mathrm{O}_{\text {IIr }}$ toward $\mathrm{Cl}$, at the same time the $\mathrm{O}_{\text {III }}-\mathrm{Al}_{\mathrm{II}}$ distance, which is the shortest in the $\mathrm{AlO}_{6}$ octahedra, and which would be increased by a displacement of $\mathrm{O}_{\mathrm{III}}$ toward $\mathrm{Cl}$, doubtless indicates a force tending to offset the restriction due to the oxygen atoms.

The above considerations indicate that the proton lies essentially along the line of centers between the $\mathrm{Cl}$ and $\mathrm{O}_{\mathrm{III}}$ atoms, and this is compatible with the bond angles at $\mathrm{O}_{\mathrm{IIr}}$. Bernal \& Megaw (1935) have pointed out that the proton in hydrogen bonding tends to assume a tetrahedral orientation with respect to the surrounding cations, as seen from the oxygen ion to which the proton is attached. Pauling suggests (private communication) that the acceptable proton positions be found by the intersection of cones of apex angle $360^{\circ}-2\left(109^{\circ} 28^{\prime}\right)$, the apices located at the oxygen ion and the cone axes directed toward the surrounding cations. As the cation-oxygen-cation angle is increased from the tetrahedral value, the possible proton positions approach one another, and when this angle reaches $141^{\circ}$ the cones become tangent and the single possible proton position is coplanar with the two cations and the oxygen ion. This is very nearly the situation at $\mathrm{O}_{\mathrm{III}}$, because the $\mathrm{Al}_{\mathrm{II}}-\mathrm{O}_{\mathrm{III}}-\mathrm{Al}_{\mathrm{II}}$ angle is $139^{\circ}$. The symmetry then places the proton along the $\mathrm{O}_{\mathrm{III}} \mathrm{Cl}$ line.

Fluorine probably does not substitute for $\mathrm{O}_{\text {III }}$, because the sum of the fluorine and chlorine crystal radii is $3 \cdot 17 \AA$, and there would be no hydroxyl bonding.
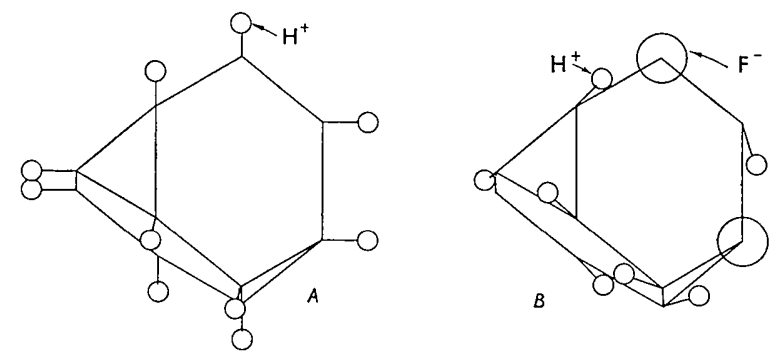

Fig. 6. The truncated tetrahedral group $\mathrm{AlO}_{4}(\mathrm{OH})_{12}$ in zunyite. In $A$, the protons are arranged in the way required by the 'coplanarity' argument. The arrangement in $B$ is the one proposed on the basis of interatomic distances, and shows the two fluorine atoms required for minimal electrostatic energy.

We now turn to the $\mathrm{O}_{\mathrm{IV}}$ atoms, of which there are 12 in the structural unit. These atoms are arranged at the corners of a truncated regular tetrahedron, shown in Fig. 6, at the center of which is the $\mathrm{Al}_{\mathrm{I}}$ atom. The $\mathrm{O}_{\text {I }}$ atoms lie at the centers of the four large faces of the truncated tetrahedron. Each of these large faces forms the face of an $\mathrm{Al}_{3} \mathrm{O}_{13}$ group (better, $\mathrm{Al}_{3} \mathrm{O}_{4}(\mathrm{OH})_{9}$ ) which attaches on the outside.

Now the bond angle $\mathrm{Al}_{I I}-\mathrm{O}_{\text {IV }}-\mathrm{Al}_{\text {II }}$ is $147^{\circ}$. If this be interpreted to require that the protons occupy the coplanar positions, as at $\mathrm{O}_{\text {III }}$, then they must stick out perpendicular to the long edges of the truncated tetrahedron, as shown in Fig. $6 \mathrm{~A}$. This places the atoms $\mathrm{O}_{\mathrm{IV}}$ and $\mathrm{O}_{\mathrm{IV}}^{\prime}$ (Fig. 5) in a non-bonding arrangement (Bernal \& Megaw, 1935), an arrangement which is unlikely in view of its expected effect on the $\mathrm{O}_{\mathrm{IV}}-\mathrm{O}_{\mathrm{IV}}^{\prime}$ distance. The $\mathrm{O}_{\mathrm{IV}}$ and $\mathrm{O}_{\mathrm{IV}}^{\prime}$ atoms are not bonded together by forces from within the truncated tetrahedron. Instead, they form one edge of a tetrahedral group of oxygen atoms with no cation at the center. Neither are the $\mathrm{O}_{I V}$ and $\mathrm{O}_{I V}^{\prime}$ atoms bonded together 
by forces from the $\mathrm{Al}_{3} \mathrm{O}_{13}$ group outside. There again they form part of a tetrahedron with no central cation, as can be seen in Fig. 5. There is therefore every reason to expect the $\mathrm{O}_{\mathrm{IV}}-\mathrm{O}_{\mathrm{IV}}^{\prime}$ distance to approach the non-bonded hydroxyl distance of $3 \cdot 2 \AA$ or greater. This expectation is substantiated in gibbsite, in which the octahedral groups distort in such a way that the oxygen atoms equivalent to $\mathrm{O}_{\mathrm{IV}}$ and $\mathrm{O}_{\mathrm{IV}}^{\prime}$ are placed at an average distance of $3 \cdot 20 \pm 0 \cdot 20 \AA$ (see Megaw, 1934). The actual $\mathrm{O}_{\mathrm{IV}}-\mathrm{O}_{\mathrm{IV}}^{\prime}$ distance is only $2.77 \AA$. Although this is notably the longest $\mathrm{O}-\mathrm{O}$ distance in the $\mathrm{Al}_{3} \mathrm{O}_{13}$ group, it falls far short of the expected nonbonded distance, and is instead a typical hydrogenbonded distance.

We therefore introduce hydrogen bonds between the $\mathrm{O}_{\mathrm{IV}}$ and $\mathrm{O}_{\mathrm{IV}}^{\prime}$ atoms by rearranging the protons according to a scheme such as shown in Fig. $6 \mathrm{~B}$, in which one proton is assigned to each long edge of the truncated tetrahedron, and one to each truncation, sticking out toward the chlorine atom. In disregarding the requirement of coplanarity we make use of the fact that the angle $\mathrm{Al}_{I I}-\mathrm{O}_{\mathrm{IV}}-\mathrm{Al}_{\mathrm{II}}$ is greater than $141^{\circ}$, and that the more nearly $180^{\circ}$ is approached, the less determinative is the tetrahedral orientation, so that the protons become free to adopt positions most favorable electrostatically. It seems clear that the configuration proposed in Fig. $6 \mathrm{~B}$, is more favorable in this way than the configuration required by coplanarity, because it reduces the repulsive potential between the $\mathrm{O}_{\mathrm{IV}}$ and $\mathrm{O}_{\mathrm{IV}}^{\prime}$ atoms. But in any case the proposed arrangement is required by the interatomic distances.

The proton arrangement proposed for the $\mathrm{O}_{\mathrm{IV}}$ atoms of zunyite allows only 10 of the 12 protons to be placed in the truncated tetrahedral group. Two more could be added, of course, by introducing two protons into positions on two of the truncated corners. This would make the $\mathrm{O}_{\mathrm{IV}}$ atoms non-bonding on these corners, but inasmuch as these atoms are held directly to the same aluminum cations no conspicuous distance effects would be expected. However, such an arrangement is bound to have higher energy (lower binding energy) than the 10-proton arrangement, and it can be avoided by replacing two of the $\mathrm{O}_{\mathrm{IV}}$ atoms by fluorine. This, indeed, appears to be the true role of fluorine in the structure. That fluorine does have a special role is suggested in a striking way by the synthesis of presumed zunyite by Schlaepfer \& Niggli (1914). The mineral was synthesized under hydrothermal conditions in the presence of a small amount of fluorine, but not without. The Zuñi Mine crystals contain consistently about $3-3.5$ atoms of $F$ out of the 18 $(\mathrm{OH}+\mathrm{F})$, which accords with the above expectations. The same is true for the new analyses of crystals from Uaxactum (Palache, 1932) and from Kazakhstan (Astashenko \& Moleva, 1939). For the Postmasburg material values of only $0 \cdot 3-0.5$ for $F$ are reported, but for two of the three analyses the sum $\mathrm{OH}+\mathrm{F}$ is low by about 2.0 and the third was considered untrust- worthy by Pauling (1933) for other reasons. Hence there seems to be support for the proposed special role of fluorine in the zunyite structure, a role which can be expressed by reformulating the composition thus: $(\mathrm{OH}, \mathrm{F})_{16} \mathrm{~F}_{2} \mathrm{Al}_{13} \mathrm{Si}_{5} \mathrm{O}_{20} \mathrm{Cl}$.

The proposed proton-fluorine arrangement is of course statistical, the configuration shown in Fig. $6 B$, being only one of many equally likely configurations.

\section{Relationship to other structures}

Zunyite is classified by Dana (1932, p. 59]) with helvite and the ultramarines, probably on the basis of morphological symmetry. There is no basic relationship, however, the only feature in common being the inclusion of chlorine or other large ions in the structures. There is no counterpart in any other known structure for the $\mathrm{Si}_{5} \mathrm{O}_{16}$ group in zunyite, whose existence conflicts with the well-known rule that silicon tetrahedra do not share corners unless the ratio $\mathrm{O}: \mathrm{Si}$ is less than 4:1 (Bragg, 1937, p. 140). The closest structural relative of zunyite is diaspore, $\mathrm{AlHO}_{2}$, which is built by linking together $\mathrm{Al}_{3}(\mathrm{OH})_{13}$ groups of the kind found in zunyite. The groups link together by sharing edges to form endless ribbons through the structure (the double rutile strings of Ewing), and the ribbons are linked together by sharing corners of aluminum octahedra and by hydroxyl bonds. The linking is such that no 'non-bonded' oxygen atoms equivalent to $\mathrm{O}_{\mathrm{IV}}-\mathrm{O}_{\mathrm{IV}}^{\prime}$ in the $\mathrm{Al}_{3} \mathrm{O}_{13}$ group occur, because every pair of oxygen atoms is common to at least one octahedral group around an aluminum atom. The nearest equivalent in diaspore of the $\mathrm{O}_{\mathrm{IV}}-\mathrm{O}_{\mathrm{IV}}^{\prime}$ pair in zunyite is a pair of hydroxyls which are an unshared edge with respect to one ribbon and a 'non-bonded' pair with respect to the adjoining one. The interatomic distance of this pair is $2.84 \AA$, which is accurately known because it is the $c$-axis length of the crystal. This distance is significantly larger than the $\mathrm{O}_{\mathrm{IV}}-\mathrm{O}_{\mathrm{IV}}^{\prime}$ distance of $2.77 \AA$ in zunyite, and provides additional support for the expected repulsion between non-bonded hydroxyl ions.

In böhmite the ribbons are linked together in a different way, with the result that $\mathrm{OH}^{-}$and $\mathrm{O}^{-2}$ positions are distinguished in the structure, a point of similarity with zunyite.

The aluminosilicate minerals andalusite, sillimanite, kyanite, topaz, and zunyite all have ratios $\mathrm{Al}: \mathrm{Si} \cong 2: 1$, and it would be desirable to give a structural interpretation of the conditions required for the stability of each. This cannot be done adequately, but it may be noted that a basic hydrothermal environment leads to topaz $\left(\mathrm{Al}_{2}(\mathrm{OH}, \mathrm{F})_{2} \mathrm{SiO}_{4}\right)$, and the additional requirement of including chlorine atoms would favor the zunyite structure.

It is a pleasure to thank Prof. Pauling for the opportunity to carry out this study, and for his interest and help in the course of the work. I am 
grateful to Dr Hughes for advice and instruction, and to the Corning Glass Works Foundation for a fellowship in support of the work.

\section{References}

Andress, K. R. \& Gundermann, J. (1934). Z. Kristal$\log r .87,345$.

Astashenko, K. L. \& Moleva, V. A. (1939). Miner. Abst. VII, 462.

Berghuts, J., Haanappel, IJ. M., Potters, M., LoopStra, B. O., MacGillavry, C. H. \& VeenendaAL, A.L. (1955). Acta Cryst. 8, 478.

Bernax, J. D. \& Megaw, H. D. (1935). Proc. Roy. Soc. $A, 151,384$.

BragG, W. L. (1937). Atomic Structure of Minerals, p. 140. Ithaca: Cornell Univ. Press.

Dana, E. W. (rev. Ford, W. E.) (1932). A Textbook of Mineralogy. New York: Wiley.

DоNониE, J. (1952). J. Phys. Chem. 56, 502.

Ewing, F. J. (1935). J. Chem. Phys. 3, 203.
HARKER, D. (1936). Z. Kristallogr. 93, 136.

HoARd, J. L. \& Grenko, J. D. (1934). Z. Kristallogr. $87,110$.

Камв, W. В. (1960). Acta Cryst. 13, 24.

MEGAW, H. D. (1934). Z. Kristallogr. 87, 185.

MeEs, C. E. K. (1954). The Theory of the Photographic Process, p. 166. New York: Macmillan.

PaLACHe, C. (1932). Am. Min. 17, 304.

PaUling, L. (1933). Z. Kristallogr. 84, 442.

Pauling, L. (1939). The Nature of the Chemical Bond. Ithaca: Cornell Univ. Press.

Penfold, B. R. \& Grigor, J. A. Acta Cryst. In press. Schlatepfer, M. \& Niggli, P. (1914). Z. anorg. Chem. $87,56$.

SмrтH, J. V. (1954). Acta Cryst. 7, 479.

TAKeI, W. J. (1957). Thesis, Calif. Inst. of Technology. Wells, A. F. (1949). Acta Cryst. 2, 175.

WELLS, A. F. (1950). Structural Inorganic Chemistry. Oxford: University Press.

Yoon, Y. K. \& Carpenter, G. B. (1959). Acta Cryst. 12, 17.

Acta Cryst. (1960). 13, 24

\title{
Accuracy of Atomic Positions in the Zunyite Structure
}

\author{
By W. BARCLAY KaMB \\ California Institute of Technology, Pasadena, California, U.S.A.*
}

(Received 14 Fiebruary 1958)

\begin{abstract}
The accuracy of positional parameters in the refined zunyite structure is estimated by four different statistical methods, including a comparison of two entirely independent refinements of the structure. The estimates show tolerable agreement, but disagree as to the importance of $F_{o}$ measurement error in affecting the parameter error. Reliable estimates of $\pm 0.008 \AA$ (standard deviation) for oxygen coordinates and $\pm 0.003 \AA$ for silicon and aluminum coordinates are obtained.
\end{abstract}

\section{Introduction}

In a separate paper (Kamb, 1960) a detailed study of the structure of zunyite $\left(\mathrm{Al}_{13} \mathrm{Si}_{5} \mathrm{O}_{20}(\mathrm{OH})_{18} \mathrm{Cl}\right)$ is reported. Because of current interest in accurate interatomic distances in silicate structures, I considered it worthwhile to compare different statistical methods for estimating the accuracy of atomic positions in the refined zunyite structure.

There are four essentially independent ways in which the accuracy of atomic positions in the structure can be estimated: (1) a priori estimation of parameter variances by the method of Booth \& Britten (1948); (2a) a posteriori estimation from the agreement of observed and calculated intensities in the least-squares refinement, or $(2 b)$ from the final difference maps by the methods of Cruickshank $(1949 a, b) ;(3)$ comparison of the results of the independent $h k 0$ and $h h l$ refinements; (4) comparison of independent $\mathrm{Si}-\mathrm{O}$ distances in

* Division of the Geological Sciences, Contribution No. 960. the same tetrahedron or in different tetrahedra if there is no preferential ordering of silicon and aluminum.

\section{A priori estimate}

The method given by Booth \& Britten (1948) and revised by Lipson \& Cochran (1953) enables a lower limit for the attainable parameter variances to be estimated from a knowledge of the measurement errors of the $F_{o}$ 's. Comparisons of two independent measurements of the $h k 0$ reflections, and also of the $h h l$, shows that for both sets of data the standard deviation estimate for the visually estimated logarithm of the intensity is $0 \cdot 05$. For the average of two such independent measurements, the standard deviation estimate of the structure factors is $0 \cdot 04\left|F_{o}\right|$. To use this information for an a priori prediction of the parameter variances by a relation of the type given by Lipson \& Cochran (1953), the high symmetry of the (100) projection used in the refinement must be 